\title{
Literatura, astronomía y política en la narrativa gráfica de magazines chilenos (1907-1915) ${ }^{1}$
}

\section{Literature, astronomy and politics in the graphic narrative of Chilean magazines (1907-1915)}

\author{
VERÓNICA RAMÍREZ \\ LORENA VALDERRAMA ${ }^{b}$ \\ ${ }^{a}$ Universidad Adolfo Ibáñez, Facultad de Artes Liberales, Chile. \\ Correo electrónico: vramirez@uai.cl \\ ${ }^{b}$ Universidad Alberto Hurtado, Facultad de Ciencias Sociales, Chile. \\ Correo electrónico: lvalderrama@uahurtado.cl
}

Este trabajo analiza la extrapolación de contenidos astronómicos a asuntos políticos, evidenciada en caricaturas y foto-reportajes publicados en los magazines chilenos Sucesos, Zig-Zag y Corre Vuela, entre 1907 y 1915. En estos dispositivos periodísticos, que funden texto e imagen, se visualiza una utilización del saber astronómico, con el propósito de ponderar o criticar situaciones políticas, así como de burlarse o lamentarse de ellas, ejercicio que se realiza mediante la aplicación de recursos literarios. En ese sentido, se estudia el aprovechamiento de la narrativa de la peligrosidad del paso del Cometa Halley de 1910, para referirse desde una perspectiva satírica a aspectos generales del gobierno de Pedro Montt (1906-1910), y por otra, se analiza el tratamiento melodramático de las diferentes fases del proyecto de construcción de un nuevo Observatorio Astronómico Nacional (1909-1913), en cuanto aspecto específico de la agenda política de Montt. La perspectiva teórica del análisis contempla los estudios de historia de la ciencia y del conocimiento, y dentro de ello las prácticas comunicativas y el papel que desempeñan los medios y los públicos de la ciencia. También se considera el estudio de la prensa, en especial, de las revistas de variedades en cuanto soportes que funden texto e imagen y responden sobre todo a un fin comercial.

Palabras clave: Astronomía, literatura, política, magazines, narrativa gráfica.

\footnotetext{
${ }^{1}$ Esta investigación se ha desarrollado en el marco de los proyectos Fondecyt/ANID №3180131 "Astronomía y literatura en Chile: diálogos y discusión en el espacio público (1880-1930)”, Fondecyt/ANID N 11190486 "Lo que auguran los astros: representación de saberes científicos y legitimación de expertos en la prensa diaria chilena (1900-1930)" y el Fondecyt/ANID N¹170625 “Observando las estrellas desde el sur del mundo: El Observatorio Astronómico Nacional de Chile (1852-1927)”.
} 
This work analyzes the extrapolation of astronomical content to political issues, evidenced in cartoons and photo-reports published in Chilean magazines Sucesos, Zig-Zag and Corre Vuela, between 1907 and 1915. In these journalistic media, which merge text and image, it is possible to visualize a use of astronomical knowledge, with the purpose of pondering or criticizing political situations, as well as mocking or lamenting them, an exercise that is carried out through the use of literary resources. In this sense, the use of the narrative of the dangerousness of the passage of Halley's Comet of 1910 is studied, to refer to general aspects of Pedro Montt's government (1906-1910) from a satirical perspective, and on the other, the melodramatic treatment of the different phases of the construction project of a new National Astronomical Observatory (1909-1913) is analyzed, as a specific aspect of Montt's political agenda. The theoretical perspective of the analysis contemplates the studies of the history of science and knowledge, specifically, of communicative practices and the role played by the media and science audiences. The study of the press is also considered, especially of variety magazines as supports that merge text and image and respond above all to a commercial purpose.

Key words: Astronomy, literature, politics, magazines, graphic narrative.

\section{INTRODUCCIÓN}

Los medios periodísticos han abordado el tratamiento de los astros y la representación de eclipses y cometas mediante distintos recursos narrativos y gráficos. La prensa, además, se ha referido a estos fenómenos para aludir a asuntos que rebasan las inquietudes meramente científicas, de tal modo que los vicios sociales, problemas económicos, tensiones políticas, entre otros asuntos, han sido asociados y representados dentro de las páginas de diarios, periódicos, revistas y otros medios de prensa, a través de choques astrales, oscurecimientos solares, conjunciones planetarias o movimientos de cuerpos celestes (Ruiz-Castell et al. 2013; Valderrama y Ramírez 2020; Ramírez y Leyton 2021).

En este trabajo se revisa este tratamiento y representación en revistas ilustradas chilenas -también llamadas revistas de variedades o magazines- de principios del siglo XX, específicamente revista Sucesos, Zig-Zag y Corre Vuela, las primeras de este tipo que circularon en el país. Se observa que estas tres publicaciones utilizaron los géneros literarios de la sátira y del melodrama para representar fenómenos y asuntos astronómicos, mediante caricaturas y foto-reportajes y, a través de ellos, se refirieron a la contingencia política y buscaron captar lectores. Así, por una parte, el avistamiento del paso del cometa Halley en 1910, y por otra, la compra estatal de nuevos instrumentos e instalaciones para el desarrollo astronómico en Chile, fueron acontecimientos representados por estas revistas mediante un tratamiento literario, y fueron usados por ellas para referirse al acontecer político y captar nuevos lectores. En los próximos apartados se demuestra que el humor y la tragedia en la narrativa gráfica analizada, se produce gracias a la aplicación de un mensaje connotativo (significado indirecto) a un fenómeno astronómico, dislocándolo y disociándolo de su marco científico (o significado directo), para aplicarlo a un problema de índole política, por 
lo que se produce una relegación de la transmisión del saber científico, para dar prioridad a la exposición del éxito y fracaso de una determinada agenda política. En específico, se estudia el aprovechamiento de la narrativa de la peligrosidad del paso del Cometa Halley de 1910, para referirse desde una perspectiva satírica a aspectos generales del gobierno de Pedro Montt (1906-1910), y por otra, se analiza el tratamiento melodramático de las diferentes fases del proyecto de construcción de un nuevo Observatorio Astronómico Nacional (19091913), en cuanto aspecto específico de la agenda política de Montt.

Los magazines surgieron en el periodo en el que la industria editorial y periodística sufrió un proceso modernizador (Alvarado 2011: 82-83). Su carácter visual y misceláneo les permitió atraer audiencias diversas. Este tipo de revistas, por un lado, ofrecía una mejor calidad gráfica y material, incluyendo fotografías e ilustraciones como elemento central; y por otro, tocaban temas diversos de la política, economía, literatura, historia y ciencias, entre otros, lo que las hacía heterogéneas y atractivas para un público variado. Además, estas revistas constituyeron verdaderas empresas comerciales, cuya subsistencia principal fue la venta de avisajes, promoviendo una cultura de consumo (Ossandón y Santa Cruz 2005).

En los magazines la transmisión de la comunicación se produce a través de dos códigos: el textual y el visual, y a principios del siglo XX, cuando surgieron estas revistas en Chile, enterarse desde la dinámica de lo visible y lo leíble simultáneamente implicaba un gesto transgresor, obligando por primera vez a sostener una mirada híbrida o "desdisciplinar", o como lo ha denominado W. J. T. Mitchell (1994), a producirse un giro visual. A esto último debe sumarse que algunas de las piezas analizadas mezclaron géneros y funciones comunicacionales distintas, como la literaria y la publicitaria, lo que también era novedoso a principios del siglo XX. Por lo que para estudiar la narrativa gráfica que fundió asuntos astronómicos con la política local en los magazines, se debe tener en consideración el carácter transgresor de estos medios para su época. En las caricaturas analizadas lo que subyace en este sentido es el rompimiento de la convergencia o diálogo entre imagen y palabra, primando no necesariamente una rivalidad entre ambos códigos, donde uno se somete al otro, pero sí una divergencia, que provoca tensión. La comicidad de las fuentes analizadas aflora de esa relación entre texto y palabra, por lo que la identificación de los lenguajes en tensión es clave. En los foto-reportajes, en cambio, texto e imagen se potencian sustancialmente, y esta última cobra un rol protagónico, buscando emocionar y sensibilizar al espectador a través de la proyección de fotografías de enormes y modernas instalaciones e instrumentos astronómicos, o mediante la incorporación de imágenes trágicas que reportan el suicidio de la máxima autoridad astronómica del país, y junto con ello, el fracaso de un gran proyecto científico.

Sucesos, Zig-Zag y Corre-Vuela no solo fueron los primeros magazines producidos en Chile que circularon en el país, sino que también fueron los más estables durante las primeras décadas del siglo XX. Estos fueron creados por Agustín Edwards Mac-Clure y Gustavo Helfmann, y "se configuraron como la respuesta burguesa-empresarial frente a los múltiples discursos culturales, literarios, artísticos, sociales, políticos, informativos, entre otros, que en 1905 configuraban públicos lectores específicos" (Alvarado 2011: 85). A pesar 
de que estos ideológicamente difundían las ideas liberales moderadas, existieron algunas diferencias de perspectivas entre los proyectos que lideró uno y otro empresario. Si bien Edwards y Helfmann se asociaron en 1919, permitiendo a partir de entonces que las revistas creadas por ambos pasaran a ser parte de la misma casa editorial, hasta entonces, los medios liderados por Edwards (Zig-Zag y Corre Vuela, entre otros) se habían caracterizado por mantener una línea editorial políticamente conciliadora, que siempre estuviera del lado del orden, representado por el gobierno de turno (Bernedo y Arriagada 2002). La revista fundada por Helfmann (Sucesos), en cambio, se caracterizó en sus primeros años por la crítica a las autoridades políticas, en general, y al gobierno de Montt, en particular. Por lo que dentro de lo que sería más tarde una misma casa editorial, existieron visiones distintas, aunque moderadas, que pudieron repercutir en el tipo de representación gráfica que se realizó sobre la situación política durante el periodo analizado.

Sucesos fue una publicación semanal fundada en Valparaíso y lanzada en 1902. Estuvo destinada a divulgar acontecimientos de la actualidad noticiosa, nacional y extranjera con un alto contenido fotográfico. En las primeras décadas se configuró como un medio donde la crónica policial y la caricatura política tenían un espacio privilegiado. Su público principal era porteño, aunque se extendió a la capital e informaba también de acontecimientos de las diversas comunidades extranjeras en el país, destacando las colonias alemana e italiana (Ossandón y Santa Cruz 2005). La homóloga de Sucesos en la capital fue Zig-Zag, lanzada en 1905 por Agustín Edwards, con una orientación más miscelánea, centrándose en eventos y noticias nacionales e internacionales y temas de literatura, artes, ciencias, moda, cocina, curiosidades y vida social. Su variedad temática era preferida por hombres y mujeres, y por profesionales de todo tipo. Por otra parte, Corre-Vuela, también lanzada por Edwards desde 1908, respondió a un proyecto medial de carácter misceláneo orientado a clases populares urbanas. No interpelaba a públicos específicos de lo popular, sino a un amplio espectro de las clases más populares de las ciudades que se identifican con los valores y acontecimientos nacionales, patrios y urbanos (Ossandón y Santa Cruz 2005). Esta última revista también incluyó como uno de sus principales componentes el humor gráfico dirigido a asuntos políticos.

La aproximación teórica a este análisis es desde la historia de la ciencia y del conocimiento, centrándose en los estudios de las prácticas comunicativas y el papel que desempeñan los medios y los espacios de comunicación (Cooter 1984; Shapin 1990). El tránsito del saber, es decir, su transmisión entre distintos lugares o comunidades (Secord 2004), así como la apropiación, reconfiguración y reinvención constante de ideas, es una perspectiva clave para un análisis como este (Raj 2007, 2013; Arabatzis et al. 2015). Enfocarse en el movimiento continuo del saber, cuya trayectoria está constituida por múltiples puntos locales de resignificación e intercambio (Roberts 2009), permite problematizar las relaciones entre los científicos o expertos, y los legos o públicos de la ciencia, tradicionalmente estudiados desde lógicas verticalistas de transmisión de conocimiento, donde aficionados, amateurs e inexpertos son considerados personas pasivas que sólo recepcionan conocimientos o entregan información (Hilgartner 1990; Nieto-Galan 2011). La perspectiva del análisis 
que se desarrollará en las próximas páginas, hará hincapié en el rol de los públicos de la ciencia en cuanto agentes activos del proceso de construcción de conocimiento, siendo una parte sustancial del circuito de comunicación de este, el que incluye a los editores y los lectores, entre otros (Chartier 2005; Darnton 2010).

Para el análisis de la relación texto e imagen se comprende una necesidad entre ambas, en el sentido de que "la imagen por sí misma, sin recurrir al lenguaje verbal, no afirma ni niega nada" (Joly 1999: 95). Por lo tanto, para reducir la polisemia en la interpretación de las imágenes, es clave analizar el comentario verbal que acompaña a aquellas (Joly 1999). De este modo, la narrativa gráfica seleccionada puede tener múltiples significaciones y prestarse a diversas interpretaciones, pero las ambigüedades que suscitan pueden disiparse mediante la contextualización y la definición de la relación texto-imagen.

Finalmente, respecto al análisis literario, se entenderá el humor como un fenómeno complejo de carácter cognitivo, psíquico y social (Pirandello 2002), que como concepto general incluye otras múltiples figuras, tales como la ironía, la comedia, la sátira, la parodia, etc. (Ruch 2002). Para el caso de los magazines seleccionados se trabajará especialmente con la sátira, porque es uno de los conceptos más recurrentes dentro del humor político (Zavitsanou 2016). Lo que sustenta el melodrama, por otra parte, es el drama del reconocimiento, el que puede darse a partir de sentimientos tales como el miedo, la lástima, el entusiasmo y la risa, y a través de circunstancias terribles, excitantes, tiernas y burlescas (Martín-Barbero \& Muñoz 1992). Todas estas formas aparecen plasmadas en la narrativa gráfica con la que estos magazines representaron al Cometa Halley, así como al proyecto astronómico financiado por el gobierno de Montt en los primeros años del siglo XX.

\section{El cometa Halley y la Caricaturización del presidente Pedro Montt}

Un choque real entre un astro y nuestro planeta efectivamente podría ocasionar la destrucción de este último. Seguramente la fatalidad de un acontecimiento como este superaría todas nuestras capacidades de reacción, produciéndose un daño que afectaría a la Tierra en su totalidad. En los magazines estudiados esta vulnerabilidad humana frente a un fenómeno natural de tal magnitud es equiparada a los nefastos efectos que pueden ocasionar algunas personas dentro de una sociedad, como es el caso de las fatales repercusiones de las acciones de algunos dirigentes políticos. Esta comparación entre ambos agentes dañinos (entre los astros y los políticos) produce una relación cómica derivada de la descontextualización de la analogía, así como de la imagen tragicómica que evoca la eventualidad de que un personaje político pueda provocar daños parecidos a una catástrofe celestial.

Los augurios astronómicos con repercusiones funestas se sustentan, por lo general, en hipótesis posibles pero que no acontecen, particularidad de la que se burlaron los magazines estudiados. Lo lógico es que la mofa recaiga en las personas que plantean y defienden falsas predicciones, pero durante el paso del Cometa Halley en 1910 el ejercicio 
satírico se complejizó y utilizó para aludir a otras personalidades no astronómicas, que al igual que estas, también habían sido protagonistas de promesas sin cumplir, según la perspectiva de la opinión pública. En los magazines revisados estas personalidades pertenecieron en su mayoría al mundo político. De este modo, los falsos augurios asociados al paso del Cometa Halley en 1910, fueron aplicados a las fallidas promesas de la agenda política del presidente Pedro Montt.

El contexto político de 1910 estuvo marcado por la celebración de los 100 años de la independencia de Chile, pero también por el cumplimiento del cuarto año de mandato de Pedro Montt que se había destacado por la reconstrucción de Valparaíso, tras el terremoto de 1906, por dos grandes proyectos ferroviarios que permitirían conectar a la capital con las zonas del sur del país y con Bolivia, y por el mejoramiento de la infraestructura para distintas instituciones estatales, especialmente de aquellas dedicadas al desarrollo científico. En materia económica, los cuatros años de gobierno de Montt se habían caracterizado por un déficit presupuestario constante, inflación, un aumento de la deuda externa y un alto gasto público principalmente en infraestructura. En cuanto a la política interna, el gobierno de Montt había demostrado en 1907 una dura represión del movimiento obrero, cuya mayor expresión fue la matanza de los huelguistas en la Escuela de Santa María en Iquique, cuyo grupo se conformaba por trabajadores del salitre. Además, había tenido fuertes enfrentamientos con el parlamento, ya fuera con los bloques conservadores o liberales, vetando leyes, sobre todo aquellas que postergaban el restablecimiento del patrón oro.

Esta incongruencia entre las expectativas generadas por el gobierno y la realidad provocaba una paradoja, la que a su vez pudo promover el uso de la ironía. Esta última, sin embargo, solo puede ser comprendida por quienes participan de un cierto contexto (Grice 1975), pues solo así se puede procesar el significado literal del mensaje (Giora 1999). El contexto político era, sin dudar, conocido por quienes produjeron estos magazines, pero si estos también bromearon ampliamente con los fallidos vaticinios sobre el cometa Halley, se puede inferir que la astronomía, o que al menos el Halley en particular, hubo de ser en esos años un asunto sumamente familiar para las audiencias (Ramírez 2019), ya que, de otro modo, habría sido difícil sostener cruces entre astronomía y política.

A fines del año 1909 la prensa en Chile comenzó a anunciar el acercamiento del cometa Halley, cuya máxima aproximación con la Tierra, según los cálculos, se alcanzaría en mayo de 1910. Desde estos primeros anuncios, los magazines estudiados cubrieron la noticia mediante un tono fatalista, basándose en la predicción que circulaba en el resto del mundo, sobre un posible choque de este astro y nuestro planeta. El augurio había ido tomando fuerza desde que el astrónomo y divulgador francés Camille Flammarion publicó en la revista L'Astronomie las eventuales consecuencias que podría producir un encuentro como este, texto que fue prontamente interpretado por la prensa como un vaticinio declarado por parte del científico. Aunque Flammarion explicó en un nuevo texto publicado en Le Petit Journal que su intención no había sido augurar el fin del mundo, sino tan solo proyectar posibles consecuencias a partir del fenómeno, la noticia de que la Tierra explotaría en pocos meses recorrió gran parte del orbe y se instaló con fuerza en el imaginario popular, incluso 
de públicos de zonas periféricas, como lo era Chile en esa época para el desarrollo de la ciencia global (Ruiz-Castell et al. 2013; Ramírez y Leyton 2021).

Las revistas Sucesos, Zig-Zag y Corre-Vuela aprovecharon la oportunidad que brindaba este fenómeno celeste para captar nuevos lectores. Así, durante los primeros meses del año 1910, varias de sus páginas abordaron la temática desde las más variadas perspectivas: las portadas, la publicidad, la sección literaria, los reportajes, todo se enfocó en el cometa Halley (Ramírez y Leyton 2021), lo que responde a la apropiación del saber por parte de los públicos de la ciencia, como plantean Roger Chartier (2005) y Robert Darnton (2010). Las revistas fueron persistentes en comunicar simultáneamente el carácter peligroso e inofensivo del astro, sin preocuparse de la contradicción que ello suscitaba, lo que a su vez dio paso al dualismo del tratamiento del portento celeste, con una mirada trágica y cómica a la vez.

Tal como se ha señalado, el saber astronómico respecto al Halley permeó hacia la arena política, y en los magazines esa transmisión se hizo sobre todo desde la mirada humorística. A los pocos meses de haber asumido el gobierno Pedro Montt, estas revistas comenzaron a vincularlo con el Cometa. Zig-Zag, por ejemplo, publicó en marzo de 1907 una caricatura titulada "Observando el cometa", en la que se ve al mandatario a la derecha con unos binoculares, junto a otro personaje que mira al cielo a través de un telescopio, y que calza con la descripción física de Albert Obrecht, director del Observatorio Astronómico Nacional hasta el año 1908.

Figura 1. "Observando el cometa". Zig-Zag, 31 de marzo de 1907.

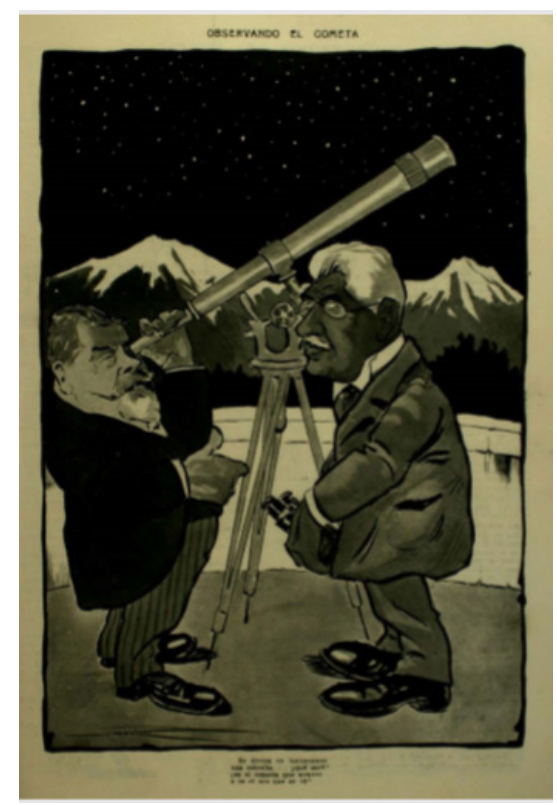


La leyenda en la parte baja de la ilustración dice lo siguiente: "Se divisa en lontananza una estrella... ¿Qué será? ¿Es el cometa que avanza o es el oro que se va?” (Zig-Zag 1907a). La huida del oro alude a que dentro de las propuestas del gobierno de Montt se encontraba el restablecimiento del régimen del patrón oro, es decir, del sistema en que el valor monetario se fija en términos de una determinada cantidad de oro, ya que la ley promulgada en 1904 en favor de la emisión de papel moneda y la postergación de la conversión monetaria habían provocado la quiebra de varias compañías. El presidente Montt se había propuesto vetar dicha ley, pero sus ministros se opusieron, por lo que se vio obligado a frenar sus intenciones. De allí que el ilustrador, cuya firma es ilegible, se le haya ocurrido bromear con la situación. Proviniendo de revista $Z i g$-Zag, puede verse que la crítica es bastante moderada y que incluso podría estar manifestándose como un llamado a los ministros y a quienes se opusieron a los propósitos del presidente. La comicidad aflora en esta caricatura producto de la asociación del cometa y del oro atendiendo a dos eventos de distinta naturaleza que habían generado expectación en la sociedad. La ironía parece ser el eslabón entre ambos objetos, la cual estaría operando, si aplicamos el concepto de María Belén Hernández (1999), como un discurso que descubre una verdad latente. La verdad, en este caso, corresponde al hecho de que los intentos de Pedro Montt por volver al régimen de moneda convertible, era "una batalla que, dada la mayoría de papeleros en el Congreso, tenía perdida de antemano" (Baeza 2008: 62).

En marzo de 1910, cuando el cometa Halley ya había acaparado la atención de la población, revista Sucesos publicó la siguiente portada titulada "El cometa de 1911".

Figura 2. "El cometa de 1911". Portada revista Sucesos, 17 de marzo de 1910.

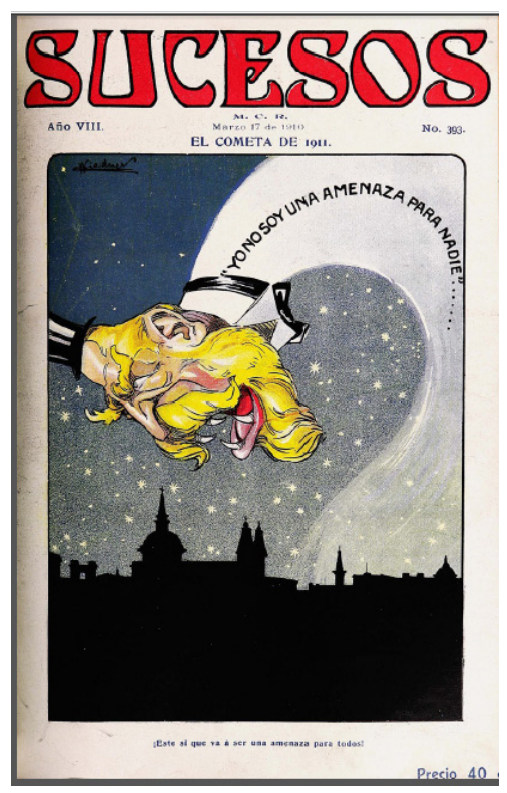


En ella la alusión al inminente acercamiento del cometa Halley, se traslapa a otra situación política también vinculada en cierta medida con el gobierno de Pedro Montt. El cometa tiene rostro y en su cola asegura no ser una amenaza para nadie. Este rostro se asocia al candidato liberal-demócrata de las futuras elecciones presidenciales de 1911, Juan Luis Sanfuentes, quien fue electo en la votación de 1915. La caricatura incluye una leyenda abajo que versa así: "Este sí que va a ser una amenaza para todos" (Sucesos 1910a), lo que puede comprenderse como un sutil apoyo a Agustín Edwards Mac-Clure de parte de su futuro socio Gustavo Helfmann, ya que el fundador de revista Zig-Zag y Corre-Vuela era el candidato del partido nacional en las elecciones de 1911, el mismo al que pertenecía Pedro Montt y el opuesto al de Juan Luis Sanfuentes. Esta votación nunca se llevó a cabo, debido a que la muerte del presidente Pedro Montt en agosto de 1910, así como el fallecimiento de su vicepresidente antes de que concluyera el mismo año, llevaron a que la asamblea eligiera a un nuevo mandatario, asumiendo Ramón Barros Luco hasta 1915. En esta caricatura dialogan la sátira y la ironía nuevamente, y esto se produce a través de la tensión entre texto e imagen. Por una parte, el mensaje escrito dice exactamente lo contrario a lo que quiere transmitir la gráfica, es decir, es irónico; y por otra, se ridiculiza a Sanfuentes como figura política con un fin determinado: apoyar la candidatura de Agustín Edwards Mac-Clure. La sátira se ha desprendido en la modernidad de su origen netamente literario para referirse a un cierto tono para ridiculizar a personas y situaciones concretas (Simpson 2003). Entre los teóricos de la sátira, Matthew Hodgart (1969) se refiere a ella como un proceso de ataque a través de la ridiculización, para conseguir determinados fines, modo en que justamente funciona la caricatura de los políticos en los ejemplos revisados. La consecución de fines en este caso podría definirse, por una parte, como el intento por transparentar ciertas situaciones críticas del devenir político, y por otra, como la búsqueda de entretener y captar nuevos lectores. En lo primero, es decir, en el propósito de revelar problemáticas de índole política, la sátira funciona en estos magazines asociada a la ironía, ya que entre las múltiples definiciones que se le han dado a esta última esta funciona como un discurso transgresor del registro cómico, a través del cual se descubren verdades ocultas o latentes, así como se desmitifican o deslegitiman determinadas lógicas (Hernández 1999). 
Figura 3. "De madrugada”. Portada revista Sucesos, 12 de mayo de 1910.

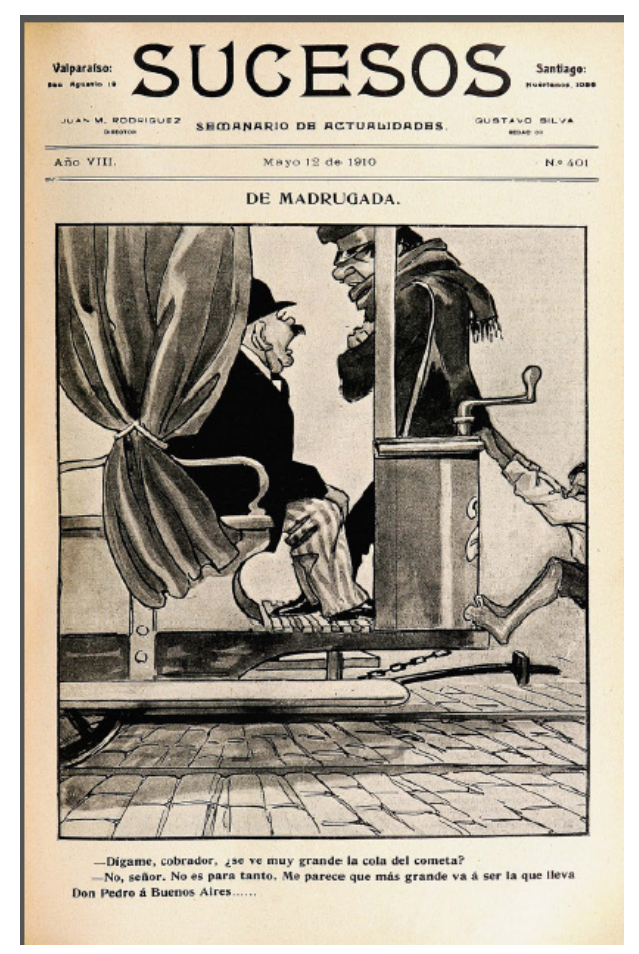

El 12 de mayo de 1910, a tan solo seis días de que el cometa Halley alcanzara su máximo acercamiento con nuestro planeta, Sucesos volvió a asociar el fenómeno astronómico con la situación política. En este caso, la cola del cometa es la que se roba la atención, y es la que se relaciona con una nueva acción del presidente Pedro Montt. Este último había decidido viajar a la celebración del centenario de Argentina a fines de mayo, y la prensa posó todos sus sentidos en la gran comitiva que lo acompañaría a esta actividad diplomática. La cola del cometa, por otra parte, se había robado la atención del público, debido a que el principal fundamento de la peligrosidad del astro era la composición de su cauda, la cual estaba compuesta por gases altamente tóxicos para los seres humanos, como lo habían podido determinar los análisis espectroscópicos, y se temía que su paso cercano permitiese su interacción con la atmósfera terrestre (Ruiz-Castell et al. 2013). El humor de esta última caricatura se sustenta en que uno de sus personajes otorga mayor relevancia y envergadura a la "cola" o comitiva que seguiría al presidente chileno al otro lado de la cordillera, que a la toxicidad letal de la cola del cometa Halley, como puede leerse en las líneas inferiores de la página: “-Dígame, cobrador, ¿se ve muy grande la cola del cometa? -No señor. No es para tanto. Me parece que más grande va a ser la que lleva don Pedro a Buenos Aires..." (Sucesos 1910b). 
La celebración de Argentina era esperada también por Chile, debido a que lo que ocurriera en mayo al otro lado de la cordillera, podría servir de ejemplo para la celebración que se realizaría en Chile en septiembre de ese mismo año (Baeza 2008). El problema era que no existía mucho ánimo para festejos por parte de la población, debido a que los estragos causados por el terremoto de 1906 aún mantenían sus efectos, lo que podía sumarse al pronunciado problema social casi insostenible debido a la gran emigración hacia las ciudades, pero sobre todo a la decadencia de la legitimidad de la elite oligárquica (Baeza 2008). De este modo, la insistencia en la celebración del Centenario y el gasto fiscal destinado a ella en dicho contexto, podrían haber sido percibidos por parte de la sociedad como una cuestión absurda y prescindible.

La última caricatura seleccionada data del mismo día de la máxima aproximación del Cometa Halley a la Tierra, es decir, del 18 de mayo de 1910. Publicada en revista CorreVuela, la pieza representa al político Fernando Lazcano Echaurren observando el cielo con un largavista, y a su espalda se esconden unos individuos que expresan estar aterrados. El dibujo titulado "Dos fuerzas iguales” incorpora abajo la siguiente leyenda: “QQué hacen ustedes aquí, en día crítico, guarecidos detrás de don Fernando?” (Corre-Vuela 1910). A lo que aquellos responden: "Precisamente, porque este es el único punto seguro del planeta, pues sabido es que un cometa con otro cometa no se hacen nada” (Corre-Vuela 1910).

Figura 4. "Dos fuerzas iguales". Portada revista Corre-Vuela, 18 de mayo de 1910.

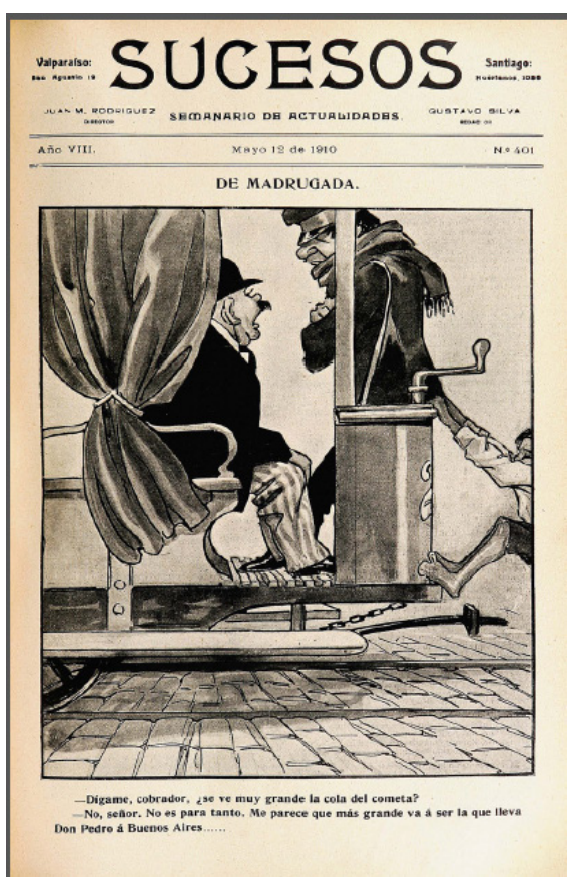


Fernando Lazcano, político liberal que presidió la cámara del Senado reiteradas veces durante los primeros años del siglo XX, fue a su vez el candidato opositor de Pedro Montt en 1906, y contra quien este último ganó la banda presidencial. Tras su derrota se convirtió en uno de los principales opositores del gobierno de Montt. La fuerza equiparada entre el cometa y don Fernando, puede extrapolarse en esta caricatura a la problemática relación entre el parlamento, presidido por Lazcano, y el poder ejecutivo, presidido por Montt, que en ese momento parecían sostener dos fuerzas opuestas pero iguales, situación que por una parte impedía el avance de la agenda política de Montt, pero al mismo tiempo, evitaba que uno u otro bando aprobara una nueva iniciativa fallida y perjudicial. El cometa en este caso es representado como un fenómeno que mantiene paralizada la solución del debate político, y la sátira nuevamente sustenta la comicidad de la narrativa gráfica.

En las caricaturas anteriores es posible constatar que la sátira y en apoyo de ella, la ironía, facilitaron la analogía entre el fenómeno astronómico y el acontecer político en estos magazines. Asimismo, en las cuatro piezas puede observarse que la relación entre la palabra y la imagen está respondiendo a una tensión entre el fenómeno astronómico y la situación política, en la que ambos se disputan el ser más o menos nocivos para la población. El temor a estos eventos (al astronómico y al político), en ese sentido, introduce un componente trágico al humor satírico, desplazándose en cierto sentido hacia la tragicomedia, lo que demuestra la agencia de los públicos de la ciencia para apropiarse del saber astronómico de las más diversas y múltiples maneras. El rol activo que ejercen los públicos de la ciencia en el modo en que circula y se comunica el saber astronómico, en este caso, influye tanto en su materialidad -soporte- como en su mensaje -significado- (Broks 1993). De este modo los públicos serían profundamente activos en los procesos de interpretación, traducción y apropiación de saberes, haciendo suyos estos, como una forma de re-producirlos y transformarlos (Raposo et al. 2014).

\section{Del optimismo a la tragedia: El Observatorio Nacional en la mira de los magazines}

Las primeras décadas del siglo XX en Chile, y sobre todo los años del gobierno de Pedro Montt (1906-1910), estuvieron marcados por la creación de centros de observación de fenómenos naturales e investigación especializada. Montt pertenecía al Partido Nacional y estaba decidido a formar un gobierno de alianza entre conservadores y liberales. Su vínculo con lo científico venía desde la década de 1880 en que había sido ministro de educación (Ministerio de Instrucción Pública), llevando a cabo una reforma educacional y contratando para ello principalmente a pedagogos alemanes. Le tocó asumir la presidencia tras el terremoto de Valparaíso del 16 de agosto de 1906, año en que la Universidad de Chile y el Consejo Universitario propusieron al Ministerio de Instrucción Pública la creación del Servicio Sismológico, compuesto por varias estaciones repartidas en el país (Valderrama 2016). De esta forma, en 1908 se fundó el Observatorio Sismológico de Santiago y el Servicio Sismológico Nacional, que se compuso de treinta y cuatro observatorios y 
estaciones sísmicas a lo largo del país. Junto con ello, en 1910 se creó el Instituto Central Meteorológico y Geofísico, que fusionó otras instituciones dedicadas a la observación del tiempo, como la Oficina de Pronósticos Marítimos de Valparaíso y la Oficina de Previsión del Tiempo del Ministerio de Industrias y Obras Públicas, que al igual que el Servicio Sismológico, contemplaba varias estaciones en distintos puntos del territorio nacional. Por otra parte, el crecimiento de la ciudad de Santiago imposibilitaba contar con las condiciones necesarias para la observación astronómica. La ubicación del Observatorio Astronómico Nacional (OAN) en ese entonces era la Quinta Normal de Agricultura, que reunía diversas instalaciones científicas, pero su cercanía a las líneas férreas producía que los instrumentos astronómicos se descalibraran. Por estas razones, en 1908 comenzó a planificarse el traslado del OAN a las afueras de la capital, en el sector de Lo Espejo (Ristenpart 1910). La persona a cargo de este proyecto fue el director del OAN, Friedrich Ristenpart, quien, desde su llegada a Chile en 1908, causó un impacto en la prensa y en las revistas ilustradas.

Estas primeras décadas del siglo XX son además claves para el estudio de las relaciones entre ciencia, política y medios de comunicación, debido a que entonces se había instalado entre los liberales la idea de que el anhelado progreso de la nación se conseguiría mediante la ilustración de la población, que iba de la mano con el desarrollo científico y tecnológico, lo que se resumía en la convicción de que había que democratizar el saber, y de que este podía llegar a todos los grupos sociales. Bajo esta premisa de que todos pueden comprender la ciencia o que la ciencia es para todos, el conocimiento científico permeó hacia la literatura, hacia el ocio y hacia otros espacios, como un producto que ya no solo informaba, sino que también entretenía y ponía en jaque otras situaciones, como la política. Fue de este modo, además, que la ciencia entró al mercado como un objeto de negocio (Fyfe y Lightman 2007).

A diferencia de lo que se expuso en el apartado anterior, el traslado del Observatorio hacia Lo Espejo no fue cubierto por las revistas analizadas mediante caricaturas, sino a través de reportajes hechos en terreno, que incluyeron fotografías de la construcción y de las personas involucradas. Este tipo de presentación del acontecer astronómico fue cubierto con seriedad y optimismo a partir de 1909, proyectando avances científicos y transmitiendo esperanza de que el nuevo observatorio alcanzaría estándares internacionales. Sucesos, por ejemplo, cubrió fotográficamente el primer tijeral de las obras, con la asistencia del personal del Observatorio y de las autoridades (Sucesos 1910c). 
Figura 5. "El nuevo observatorio astronómico". Sucesos, 17 de marzo de 1910.

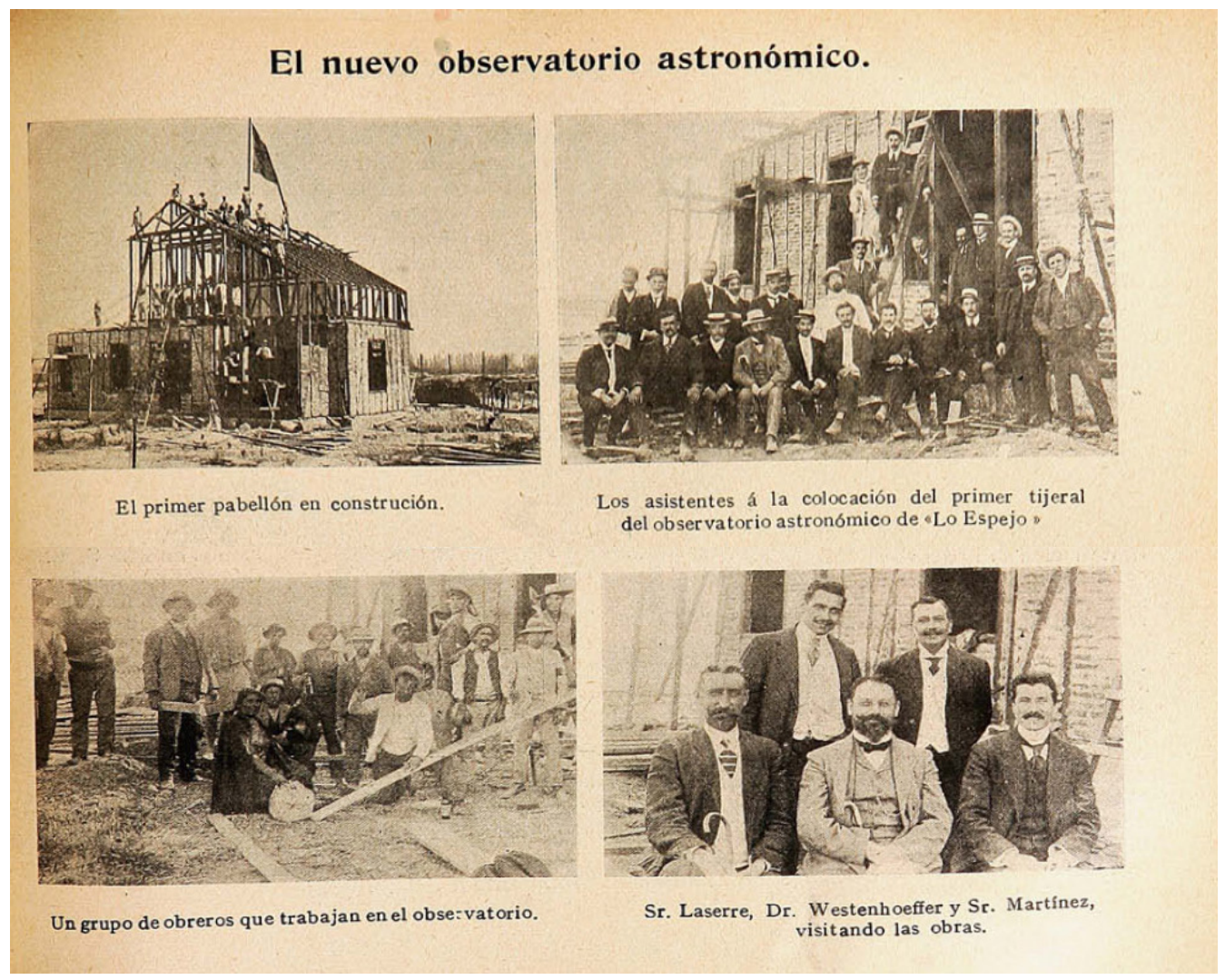

Con esta cobertura se puede apreciar la existencia de un apoyo al OAN no solo de parte del gobierno, sino también de los medios de comunicación. De hecho, el proyecto de Lo Espejo estaba contemplado desde la contratación de Friedrich Ristenpart como director del Observatorio en 1908 e incluía también el desplazamiento del futuro Instituto Central Meteorológico y Geofísico, además de todas las instalaciones habitacionales para que viviera allí el personal de ambas instituciones (Ristenpart 1910).

En 1909, la revista Sucesos ya había publicado una noticia donde se entregaban detalles sobre el nuevo observatorio. Acompañado de fotografías sobre las visitas de autoridades, el equipamiento científico, los pabellones y el personal astronómico, el reportaje elogiaba la administración de Friedrich Ristenpart y daba cuenta de cómo estas nuevas instalaciones pondrían a Chile en un circuito astronómico de primer nivel, al menos en Sudamérica. 
Figura 6. "Observatorio Astronómico de Santiago". Sucesos, 17 de junio de 1909.

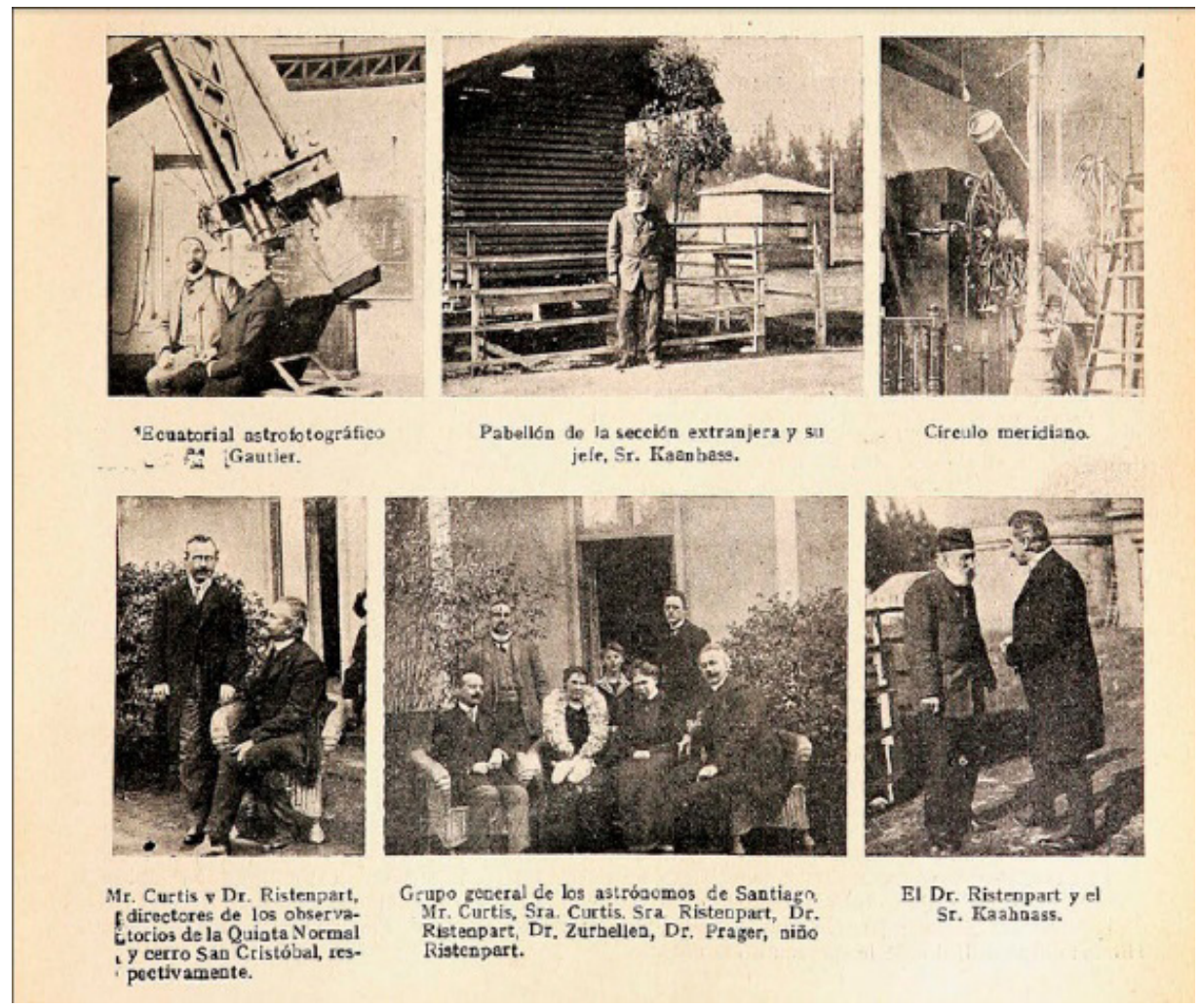

Si bien la revista menciona en este reportaje las aportaciones del gobierno de Pedro Montt, señalando la contratación de los astrónomos alemanes Walter Zurhellen y Richard Prager, al parecer, para Sucesos, la responsabilidad de este logro recaía sobre todo en Ristenpart, de quien no sólo elogiaba su capacidad científica, sino la proyección que tendría el Observatorio bajo su dirección, alzándolo como el gran protagonista de este avance:

Desde que el Dr. Federico Ristenpart tomó la dirección del Observatorio Astronómico Nacional, los servicios de esta oficina han entrado a un camino de visible progreso; y si el gobierno continúa prestando atención e interés a las indicaciones del Dr. Ristenpart, podrá en breve tiempo el país enorgullecerse de poseer un observatorio astronómico que se halle a la altura de los adelantos modernos de esta ciencia (Sucesos 1909). 
Los magazines complementaron este discurso optimista para la ciencia astronómica, con foto-reportajes de observatorios atractivos emplazados en otras partes del mundo, potenciando, de este modo, la mirada positiva hacia el desarrollo de esta disciplina en Chile.

Sin embargo, en agosto de 1910, y tras una larga enfermedad, murió el presidente Pedro Montt en Alemania, donde fue en busca de tratamiento, siendo posteriormente electo el liberal Ramón Barros Luco (1835-1919). Si bien el traslado del Observatorio hacia Lo Espejo estaba contemplado que finalizara en 1913, tras la muerte de Montt la institución dejó de recibir el apoyo económico necesario para concluir el proyecto. Los magazines dieron cuenta rápidamente de esta problemática dilucidando, a diferencia de los optimistas reportajes anteriores, un futuro trágico para la astronomía nacional. Zig-Zag, por ejemplo, mencionó en 1911, que si bien el Estado estaba haciendo un sacrificio al apoyar este traslado, el esfuerzo merecería la pena por lo réditos científicos que ello podría traer: "Si se ha decidido nuestro Gobierno a hacer sacrificios que a primera vista parecen no estar en proporción con el Erario de la Nación, por una de ellas, la astronómica, ha sido precisamente porque Chile está en situación insuperable para obsequiar a esta ciencia los más valiosos frutos de su trabajo" (Zig-Zag 1911). Sucesos, en cambio, cubrió el tema en 1915, cuando los recortes financieros ya habían sido tan significativos que el proyecto peligraba de ser abandonado. Esta revista acusaba que tras cinco años de trabajos la obra aún no estaba terminada, el personal del OAN recibía pagos insuficientes y que al parecer no habría una valorización política de la astronomía. "Es preciso que nuestros hombres de gobierno procuren colocar a este establecimiento científico en el rango que merece" (Sucesos 1915), afirma la revista e incorpora fotografías del personal con rostros serios y tristes.

Figura 7. “El Observatorio Astronómico de Lo Espejo”. Sucesos, 9 de diciembre de 1915.

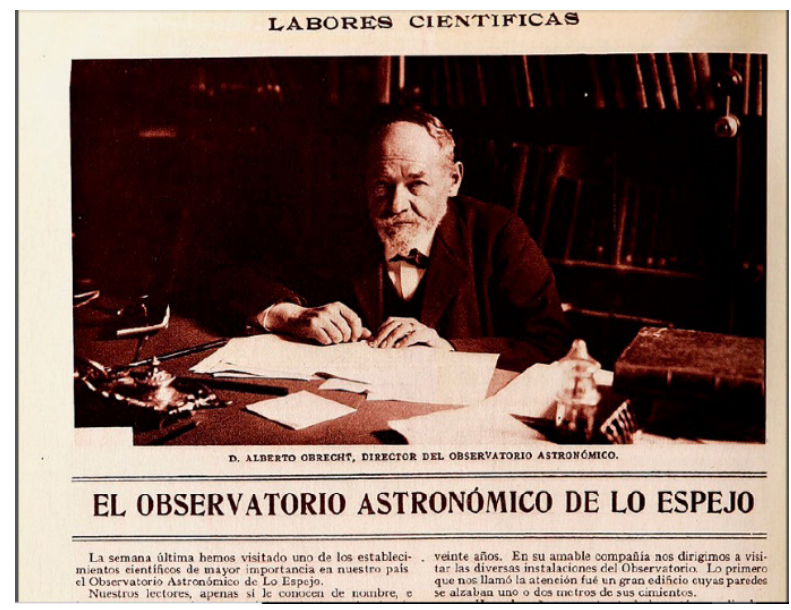


Además de los recortes económicos, este proyecto astronómico sufrió un duro revés tras la investigación sumaria de diciembre de 1912, interpuesta por el Ministerio de Instrucción Pública para indagar en la administración del Observatorio Astronómico Nacional por parte de su director Friedrich Ristenpart. La investigación no sólo demostró que existía un mal uso de los recursos fiscales, sino también de los materiales e inmuebles del observatorio, además de contar con empleados trabajando por una remuneración menor a la decretada por ley e incluso con personal que se encontraba sin contrato, situación que afectaba principalmente a las trabajadoras mujeres. ${ }^{2}$ Los magazines se pronunciaron acerca de la dramática conclusión de la dirección del astrónomo alemán, que finalizó con el suicidio de este último, por lo que la muerte del director del OAN fue representada como el final de una historia trágica que alguna vez había sido prometedora.

Sucesos dio cuenta del suicidio de Friedrich Ristenpart en abril de 1913. El acontecimiento fue cubierto en esta revista mediante un foto-reportaje, con imágenes y antecedentes del hecho bajo el estilo de crónica policial e incluyendo, por ejemplo, una fotografía de las hijas del difunto. Revista $Z i g-Z a g$, a su vez, mostró imágenes de la intimidad de la familia, incluso de la cama donde se habría disparado el científico (Zig-Zag 1913), aplicando así el componente melodramático.

Figura 8. "El trágico fallecimiento del Sr. Federico Ristenpart”. Zig-Zag, 12 de abril de 1913.

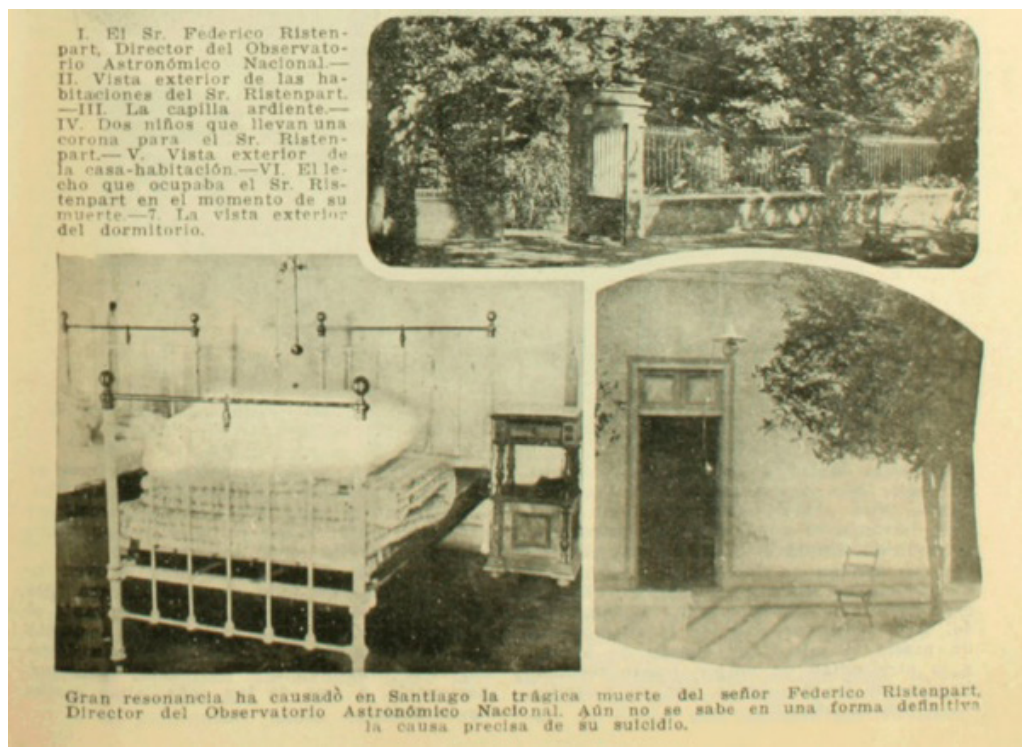

\footnotetext{
${ }^{2}$ Si bien esta situación alcanzó un clímax durante la dirección de Friedrich Ristenpart, los problemas administrativos del Observatorio Astronómico Nacional venían arrastrándose desde el siglo anterior. Esta situación produjo que la institución científica mantuviera una tensa relación con políticos y parlamentarios del país durante varias décadas (Sanhueza et al. 2020).
} 
Figura 9. "El doctor D. Federico Ristenpart". Sucesos, 17 de abril de 1913.

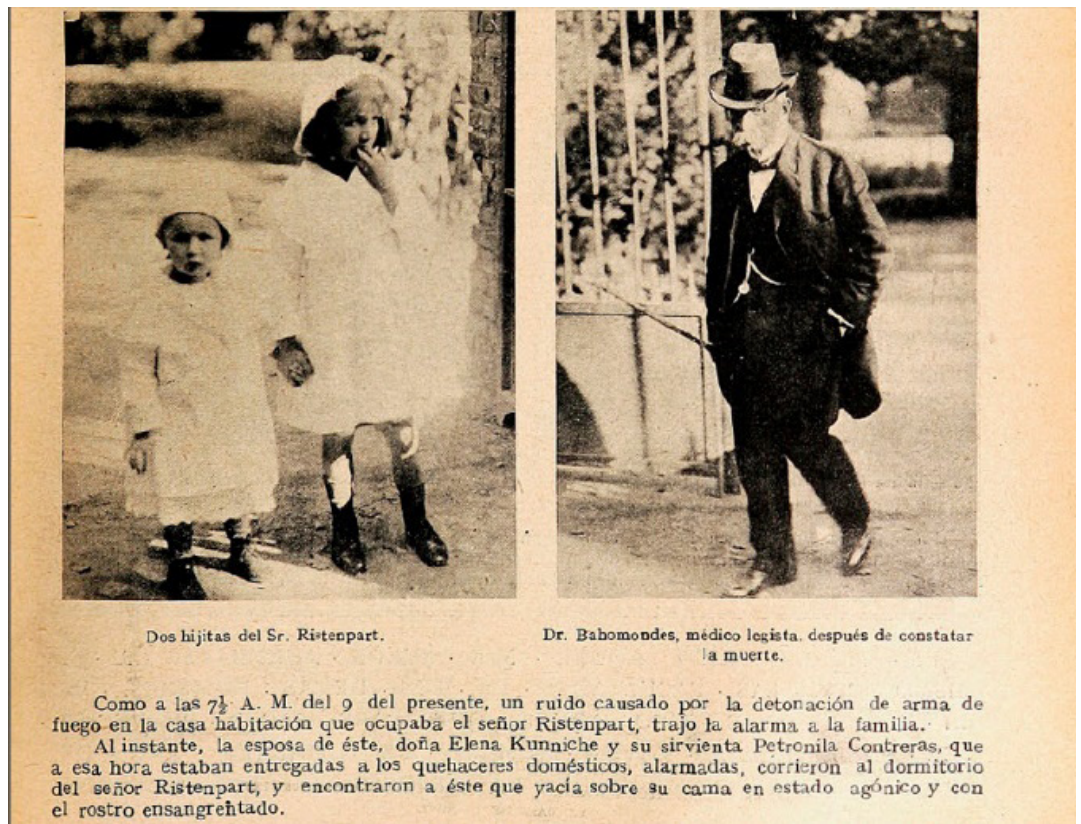

Como ha podido verse, el uso que realizan los magazines respecto al desarrollo astronómico del país supera el propósito de difundir conocimiento. Muchas veces este objetivo queda relegado a un segundo lugar, para dar mayor atención a la exposición del éxito y fracaso de una determinada agenda política. Estos proyectos periodísticos más que enfocarse en difundir la astronomía en sí misma, se centraron en las personalidades implicadas en el desarrollo de aquella, tales como el director del OAN y las autoridades políticas, y en los éxitos y fatalidades que envolvieron a estos. Así, el tratamiento de los acontecimientos en sus inicios (1909) era serio y positivo, proyectando un buen porvenir, pero en la medida en que fueron desarrollándose los distintos eventos, se volvió oscuro y negativo, coincidiendo con los pasos del malogrado proyecto científico de Ristenpart y de la fallida agenda política de Montt. Las revistas hicieron uso de ambas situaciones: de aquella que miraba con esperanza las nuevas instalaciones científicas para el país y de aquella que se quejaba y lamentaba el estancamiento de este proyecto. De este modo, el holgado apoyo financiero brindado al Observatorio por Pedro Montt, el abrupto cese de ese soporte estatal tras la muerte de Montt y el trágico suicidio de Friedrich Ristenpart, fueron todos acontecimientos aprovechados por estas revistas para atraer a sus lectores y vender más ejemplares. Esto último en un contexto mediático y cultural en que la prensa se caracterizó, entre otras cosas, por un sostenimiento mediante avisaje publicitario, por la exploración de nuevos géneros y la ampliación de las audiencias lectoras (Pizarroso 2010). 
Atraer el mayor número posible de lectores era fundamental para ampliar su rentabilidad e influencia, puesto que necesitaban perdurar autónomamente por medio de la venta y no del subsidio estatal (Gramsci 2000).

Por consiguiente, el desarrollo de la historia del Observatorio cubierta por los magazines se desplaza desde el optimismo hacia la tragedia, lo que no es necesariamente contradictorio con el humor aplicado a fenómenos astronómicos presente en las caricaturas, ya que el reconocimiento que pretende despertar el melodrama en el espectador, no solo se da mediante los sentimientos de lástima y miedo, sino también a través del entusiasmo y la risa, que pueden desprenderse de situaciones excitantes y burlescas (Martín-Barbero \& Muńoz 1992). Los magazines manejaron muy bien cada uno de estos códigos, de tal modo que transitaron desde el entusiasmo al drama, y en medio de este paso, echaron mano al humor cuando ya existía evidencia de que los augurios catastróficos no tenían sustento o que el proyecto astronómico se había estancado, asociando estos últimos con varias propuestas del programa político del presidente Montt, que también quedaron detenidas o nunca se cumplieron.

\section{Conclusiones}

En los apartados anteriores se analizó la extrapolación de contenidos astronómicos a asuntos políticos, evidenciada en caricaturas y foto-reportajes publicados en magazines chilenos entre 1907 y 1915. En estos dispositivos intermediales, que funden texto e imagen, es posible evidenciar una utilización del saber astronómico, con el propósito de ponderar o criticar situaciones políticas, así como de burlarse o lamentarse de ellas, ejercicio que, como se ha podido observar, es realizado mediante la aplicación de recursos literarios. En Sucesos, Zig-Zag y Corre-Vuela hubo un aprovechamiento del discurso de la peligrosidad del paso del Cometa Halley de 1910, para referirse desde una perspectiva satírica a aspectos generales del gobierno de Pedro Montt y, por otra parte, hubo un tratamiento melodramático de las diferentes fases del proyecto de construcción de un nuevo Observatorio Astronómico Nacional, que también conformaba un aspecto específico de la agenda política de Montt.

Como pudo verse, por una parte, el carácter intermedial de los magazines favoreció el tratamiento satírico y melodramático de los asuntos astronómicos y políticos, y por otra, el carácter misceláneo de este tipo de medios permitió el diálogo entre distintas disciplinas, tales como la literatura, la astronomía y la política. Sin embargo, como ya se esbozó, el aspecto esencial de la naturaleza de estas revistas que aúna y sostiene todos los tratamientos y relaciones antes descritas, es su propósito comercial. Estos proyectos surgieron en Chile a principios del siglo XX gracias a la modernización de la industria editorial y a la configuración de un nuevo modelo de empresa, que apuntaba a sostenerse con la venta de grandes cantidades de ejemplares, pero sobre todo de avisos publicitarios, por lo que captar nuevas audiencias era clave. Informar del acontecer no sería entonces la única estrategia 
comunicacional empleada por estas revistas, ellas se preocuparon sobre todo de entretener y de mantener un equilibrio entre ambas funciones para no perder la atención de sus lectores y para captar el interés de otros nuevos. La sátira y el melodrama, en este sentido, fueron herramientas incorporadas por estos magazines y utilizadas en una justa proporción, para no arrasar con la función informativa y no perder totalmente la credibilidad.

Lo anterior refleja que la ciencia, y en este caso particular la astronomía, se había vuelto una mercancía en este tipo de revistas, siendo utilizada para conseguir objetivos que se extendían más allá de informar el conocimiento científico. Esto último da cuenta a su vez de la capacidad que tenían estos públicos, ya sea editores, redactores, ilustradores, lectores, etc., para apropiarse y atribuir nuevos significados al saber astronómico. Ese carácter comercial de los magazines también se extendió hacia el tratamiento de la literatura y la política, utilizándolas para entretener y captar nuevos lectores. Por consiguiente, la naturaleza comercial de este tipo de medios englobó todas sus demás funciones en un nivel transversal y abarcó audiencias heterogéneas, como lo fueron las conformadas por la porteña revista Sucesos, la inclusiva Zig-Zag o la popular Corre-Vuela.

\section{Obras CITADas}

\section{Fuentes primarias}

Anónimo. 1907a. "Observando el cometa”. Zig-Zag 110. Santiago: 31 de marzo de 1907. . 1908. "Señor Federico Ristenpart". Sucesos 42. Valparaíso: 14 de octubre de 1908. . 1909. "Observatorio Astronómico de Santiago". Sucesos 354. Valparaíso: 17 de junio de 1909.

. 1910a. "El cometa de 1911". Sucesos 393. Valparaíso: 17 de marzo de 1910.

. 1910b. "De madrugada". Sucesos 401. Valparaíso: 12 de mayo de 1910.

. 1910c. "El nuevo observatorio astronómico". Sucesos 393. Valparaíso: 17 marzo de 1910.

. 1910. "Dos fuerzas iguales". Corre-Vuela 126. Santiago: 18 de mayo de 1910.

. 1911. "El nuevo Observatorio Astronómico de Lo Espejo". Zig-Zag 338. Santiago: 12 agosto 1911.

. 1913. "El Dr. D. Federico Ristenpart". Sucesos 554. Valparaíso: 17 de abril de 1913.

. 1913. "El trágico fallecimiento del Sr. Federico Ristenpart". Zig-Zag 455. Santiago: 12 de abril de 1913.

. 1915. "El observatorio astronómico de Lo Espejo". Sucesos 689. Valparaíso: 9 diciembre 1915.

Max. 1912. "Don Federico Ristenpart, Director del Observatorio Nacional". Zig-Zag 395. Santiago: 14 septiembre 1912.

Ristenpart, Federico. 1910. "El Observatorio Astronómico en 1909". Anales de la Universidad de Chile 127: 737-757. 
Fuentes secundarias

Alvarado, Marina. 2016. Revistas culturales y literarias chilenas de 1894 a 1920: Legitimadoras del campo literario nacional. Santiago: Cuarto Propio.

. 2011. "Zig-Zag y la irrupción editorial: La ciudad letrada 'zigzagueante"”. Revista Literatura y Lingüistica 23: 81-99.

Álvarez, Jesús. 1992. Historia de la prensa hispanoamericana. Madrid: Editorial Mapfre.

Arabatzis, Theodore et al. 2015. Relocating the History of Science. Essays in Honor of Kostas Gavroglu. Londres: Springer.

Baeza, Andrés. 2008. "Chile en 1910: El centenario de la muerte". En Historias del siglo XX chileno. Santiago: Ediciones B.

Bernedo, Patricio \& Eduardo Arriagada. 2002. "Los inicios de El Mercurio de Santiago en el epistolario de Agustín Edwards Mac Clure (1899-1905)”. Historia 35: 13-33.

Broks, Peter. 1993. "Science, media and culture: British magazines 1890-1914". Sci 2: 123-139.

Chartier, Roger. 2005. El mundo como representación. Estudios sobre historia cultural. Barcelona: Editorial Gedisa.

Cooter, Roger. 1984. Cultural Meaning of Popular Science: Phrenology and the Organization of Consent in Nineteenth-Century Britain. Cambridge: Cambridge University Press.

Correa, Sofía et al. 2001. Historia del siglo XX chileno. Santiago: Editorial Sudamericana.

Darnton, Robert. 2010. El beso de Lamourette. Reflexiones sobre historia cultural. Buenos Aires: Fondo de Cultura Económica.

Fyfe, Aileen \& Bernard Lightman. 2007. Science in the Marketplace. Nineteenth Century Sites and Experiences. Chicago: The University of Chicago Press.

Giora, Rachel. 1999. "On the Priority on the Salient Meanings: Studies of Literal and Figurative Lenguage". Journal of Fragmatics 31.7: 919-929.

Gramsci, A. 2000. Cuadernos de la cárcel. Vol. 6. Ciudad de México: Ediciones Era.

Grice, Paul. 1975. "Logic and Conversation". En Syntax and Semantics. New York: Academic Press. 41-58.

Hernández, María Belén. 1999. "El humor, la ironía y el cómico: códigos transgresores de lenguajes e ideologías”. Signa: revista de la Asociación Española de Semiótica 8: 217232.

Hilgartner, Stephen. 1990. "The dominant view of popularization: conceptual problems, political uses". Social Studies of Science 20: 519-539.

Hodgart, Mathew. 1969. La Sátira. Madrid: Editorial Guadarrama.

Joly, Martin. 1999. Introducción al análisis de la imagen. Buenos Aires: La Marca.

Martín-Barbero, Jesús \& Sonia Muñoz. 1992. Televisión y melodrama Géneros y lecturas de la televisión en Colombia. Bogotá: Tercer Mundo.

Mitchell, W. J. T. 1994. Picture Theory: Essays on Verbal and Visual Representation. Chicago: University of Chicago Press. 
Nieto-Galan, Agustí. 2011. Los Públicos de la Ciencia. Expertos y profanos a través de la historia. Madrid: Marcial Pons.

Ossandón, Carlos \& Eduardo Santa Cruz. 2005. El estallido de las formas: Chile en los albores de la "cultura de masas". Santiago: Lom.

Pirandello, Luigi. 2002. "Esencia, Caracteres y materia del humorismo". CIC Cuadernos de Información y Comunicación 7: 95-130.

Pizarroso, Alejandro. 2010. "El periodismo en el primer tercio del siglo XX". Arbor 186: 45-54.

Raj, Kapil. 2007. Relocating Modern Science. Circulation and the Construction of Knowledge in South Asia and Europe, 1650-1900. Nueva York: Palgrave Macmillan.

. 2013. "Beyond Postcolonialism ... and Postpositivism: Circulation and the Global History of Science”. Isis 104.2: 337-347.

Ramírez, Verónica. 2019. "Expertos y profanos: Circulación del saber astronómico en magazines chilenos”. Revista Humanidades 40: 235-272.

Ramírez, Verónica \& Patricio Leyton. 2021. "El rastro del cometa Halley: circulación y legitimación del saber astronómico en Chile (1910)”. Historia UC 54.1: 247-278.

Raposo, Pedro et al. 2014. "Moving Localities and Creative Circulation: Travels as Knowledge Production in 18th-Century Europe". Centaurus 56: 167-188.

Roberts, Lissa. 2009. "Situating science in global history: local exchanges and networks of circulation". Itinerario 33.1: 9-30.

Ruch, Willibald. 2002. "Humor Research". 14th Conference of the International Society of Humor Studies. Bertinoro, Italy.

Ruiz-Castell, Pedro, Ignacio Suay-Matallana y Juan Marcos Bonet. 2013. "El cometa de Halley y la imagen pública de la astronomía en la prensa española de principios del siglo XX”. Dynamis 33.1: 169-193.

Sanhueza, Carlos, Lorena Valderrama, Stefan Meier y José Soto. 2020. “Todos los instrumentos están en buen estado. Controversias en torno al funcionamiento de los telescopios del Observatorio Astronómico Nacional de Chile en el Siglo XIX”. Asclepio 72.1: 300.

Secord, James. 2004. "Knowledge in Transit”. Isis 95.4: 654-672.

Shapin, Steven. 1990. Science and the Public. In Companion to the History of Modern Science. London: Routledge.

Simpson, Paul. 2003. On the Discourse of Satire: Towards a Stylistic Model of Satiric Humour. Amsterdam/Philadelphia: John Benjamins.

Valderrama, Lorena \& Verónica Ramírez. 2020. Lo que auguran los astros. Espectáculos, maravillas y catástrofes en la prensa chilena (1868-1912). Santiago de Chile, RIL.

Valderrama, Lorena. 2017. “Observando la catástrofe: terremotos y conocimiento sísmico en Chile (1868-1912)”. Tesis para la obtención del título de Doctor en Historia de la Ciencia y Comunicación Científica por la Universidad de Valencia. . 2016. "La catástrofe anunciada: terremotos y predicciones en la prensa diaria chilena (1906-1912)”. En Correa, María José, Andrea Kottow y Silvana Vetö (eds.). 
ESTUDIOS FILOLÓGICOS

Ciencia y espectáculo. Circulación de saberes cientificos en América Latina, siglos XIX y $X X$. Santiago de Chile: Ocho Libros. 169-195.

Zavitsanou, Theofylakti. 2016. "Humor y discurso político: el humor como recurso de opinión y crítica en la prensa contemporánea griega y española”. Tesis para optar a grado de Doctor, Universitar Pompeu Fabra, Departamento de Comunicaciones. 
